COMECHINGONIA. Revista de Arqueología. Vol. 19, n 1. Primer semestre de 2015. ISSN: 0326-7911

\title{
INDICADORES PALEOINDIOS EN LA PROVINCIA DE ENTRE RÍOS (ARGENTINA).
}

\section{PALEOINDIANS INDICATORS IN THE ENTRE RÍOS PROVINCE (ARGENTINA).}

\author{
Juan Carlos Castro $^{1}$ y Enrique Terranova ${ }^{2}$ \\ ${ }^{1}$ División Arqueología, Facultad de Ciencias Naturales y Museo, Universidad Nacional de La \\ Plata, Paseo de Bosque S/N, (1900) La Plata; Departamento de Antropología, Museo de \\ Ciencias Naturales y Antropológicas "Prof. Antonio Serrano". Carlos Gardel 62, (3100) Paraná. \\ E-mail: castro_museoserrano@yahoo.com.ar \\ 2 CONICET, División Arqueología, Facultad de Ciencias Naturales y Museo, \\ Universidad Nacional de La Plata, Paseo de Bosque S/N, (1900) La Plata. \\ E-mail: quiqueterra@yahoo.com.ar
}

Presentado: 23/4/14 - Aceptado: 29/5/2015

\section{Resumen}

El presente trabajo da a conocer nuevos hallazgos arqueológicos en la provincia de Entre Ríos vinculados al poblamiento inicial americano. Se presentan tres artefactos líticos, dos puntas de proyectil y una piedra discoidal. Los hallazgos fueron realizados en distintos contextos; las puntas mediante tareas de prospección en el departamento Villaguay y el lito discoidal a partir de un trabajo sobre colecciones en el departamento Gualeguaychú. Estos hallazgos manifiestan la importancia potencial de la región en relación a la ocupación humana temprana, como ocurre en áreas circundantes donde las evidencias arqueológicas son abundantes.

Palabras clave: punta cola de pescado, punta Pay Paso, lito discoidal, poblamiento temprano, Nordeste argentino

\begin{abstract}
In this work we presented new archaeological finds in the province of Entre Rios, linked to the American settlement. Lithic artifacts are three, two projectile points and a discoidal stone. The findings were made in different contexts, the tips through tasks of prospecting in the Villaguay Department and discoidal stone from collections in the Gualeguaychu Department. These findings show the importance of the region in relation to early human occupation, as in surrounding areas where archaeological evidence are abundant.
\end{abstract}

Keywords: Fishtail point, Pay Paso point, discoidal stone, early settlement, Northeastern Argentina 


\section{Introducción}

El poblamiento humano temprano de la provincia de Entre Ríos ha sido un tema referido en algunos trabajos arqueológicos del área (Rodríguez 2005, 2006; Serrano 1972, entre otros), pero nunca ha sido discutido en base a evidencia empírica concreta. Hasta el momento el problema fundamental ha sido la ausencia de artefactos arqueológicos diagnósticos vinculados al poblamiento temprano, la ausencia de dataciones tempranas y la escasez de investigaciones sistemáticas.

En este trabajo se presenta nueva evidencia arqueológica vinculada al poblamiento inicial de la región. Dentro de los artefactos líticos considerados como indicadores del poblamiento temprano en el cono sur de Sudamérica se incluyen por ejemplo, las llamadas puntas cola de pescado (PCP) (Castiñeira et al. 2012; Miotti 1995; Miotti y Terranova 2015; Nami 2007, 2011; Politis 1991; Prates et al. 2013), las puntas Pay Paso (Suárez 2011, 2015a) y los litos discoidales (Flegenheimer et al. 2013; Hermo et al. 2013; Jackson y Méndez 2007; Meneghin 2011; Nami 2013). Hasta el momento en la provincia de Entre Ríos no se habían registrado ninguno de estos artefactos, excepto un caso puntual de una PCP hallada en una colección y presentada recientemente (Capelletti 2011).

\section{Materiales}

Los materiales presentados corresponden al centro y este de la provincia de Entre Ríos. Se hallan estrechamente vinculados a las cuencas del río Gualeguay y del río Gualeguaychú (Figura 1A).

En el departamento Villaguay se ha registrado un pedúnculo de PCP (Figura 1B), hallado en el sitio arqueológico Paso Blanco 4 (S31.52201; O59.10849) (Castro 2013). Este sitio, donde el material arqueológico se presenta disperso en superficie, se sitúa en un área con escasa vegetación entorno a la laguna La Blanca, en las llamadas Tierras Altas de Entre Ríos. El pedúnculo se hallaba en un contexto arqueológico integrado por desechos de talla y restos de alfarería. Sus dimensiones son: ancho de la base $13.8 \mathrm{~mm}$, ancho del pedúnculo $12.7 \mathrm{~mm}$ (se refiere, sensu Suárez 2011, a la medida tomada desde un extremo al otro de los lados del pedúnculo), y espesor máximo $5.5 \mathrm{~mm}$. La pieza presenta base y lados del pedúnculo cóncavos y no posee acanaladura basal. Este tipo de puntas han sido registradas en numerosos sitios arqueológicos del continente ubicándose en un rango cronológico comprendido entre ca. 11.500 y 9000 años AP (Miotti y Terranova 2015; Prates et al. 2013).

En el mismo departamento pero proveniente de una colección particular (Colección Beltrame) se registró una punta entera con diseño Pay Paso (Figura 1C). Si bien no contamos con información precisa sobre el contexto del hallazgo, podemos decir en base 
a la información recabada que la misma fue recolectada en superficie sobre el curso del río Gualeguay en un paraje denominado El Beso, ubicado en la misma estancia donde se encuentra el sitio arqueológico Nogueira (Castro 2013; Poenitz 1970). En cuanto a las características de la pieza, ésta presenta todos los atributos tecno-morfológicos mencionados por Suárez (2011). Las dimensiones de la pieza son: largo máximo $71.2 \mathrm{~mm}$, ancho máximo $21 \mathrm{~mm}$, espesor máximo $11.4 \mathrm{~mm}$ y ancho máximo del pedúnculo 19.7 $\mathrm{mm}$. Este tipo de puntas se distribuyen geográficamente en tres áreas de la República Oriental del Uruguay, al noroeste en el río Uruguay medio y el río Cuareim, en el centro del país en el río Negro medio y el río Tacuarembó Grande, y en el sureste sobre la costa atlántica; también ha sido registrada en el sur de Brasil (Suárez 2015a, 2015b). En el sitio arqueológico Pay Paso 1, en el río Cuareim, estas puntas abarcan un rango cronológico comprendido entre ca. 9600 y 8600 años AP (Suárez 2011).

Por último, en la colección del Museo Arqueológico Manuel Almeida de la ciudad de Gualeguaychú se registró un lito discoidal (nº de catálogo 1060) (Figura 1D). Según el catálogo de la institución el mismo proviene del departamento homónimo, y fue expuesto por la acción del arado en la Estancia El Solitario ubicada al norte de la ciudad. El hallazgo se realizó sobre la margen derecha del río Gualeguaychú a $1.8 \mathrm{~km}$ de la costa sobre la llanura alta. Sus dimensiones son: diámetro máximo $95.8 \mathrm{~mm}$, diámetro mínimo $94.4 \mathrm{~mm}$, espesor máximo $37.1 \mathrm{~mm}$, espesor en el borde $30.9 \mathrm{~mm}$, y su peso es de $560 \mathrm{~g}$. La superficie del artefacto está finamente pulida, presentando solo dos marcas de impacto asociadas a una pequeña fractura probablemente producto del arado. Una característica particular de esta pieza es que posee un hoyuelo o depresión cóncava de forma circular en cada una de sus caras. Ambas depresiones están elaboradas por picado. Una de ellas presenta un diámetro máximo de $12.1 \mathrm{~mm}$ y $2 \mathrm{~mm}$ de profundidad y la otra un diámetro de $12.6 \mathrm{~mm}$ y $1.2 \mathrm{~mm}$ de profundidad. Ésta última depresión tiene un atributo distintivo, ya que presenta un grabado inciso conformado por dos líneas perpendiculares en forma de cruz. Las piedras discoidales más próximas a este hallazgo se registran en la República Oriental del Uruguay, donde se conocen diez de estos artefactos (Meneghin 2011; Nami 2013). Dos de estos presentan una concavidad esbozada en el centro de ambas caras. Uno procede del sitio Lopeteguy II ubicado en el departamento Tacuarembó; el otro procede del sitio Los Ciervos, ubicado en el departamento Lavalleja, fue recolectado in situ y datado por AMS a partir de materia orgánica asociada, otorgando una edad de $10.140 \pm 50$ años AP (López Romanelli 2012; Meneghin 2011). Por su parte un lito discoidal con hoyuelo grabado corresponde al sitio Cerro El Sombrero (Flegenheimer y Zárate 1989; Flegenheimer et al. 2013), en el sur de la provincia de Buenos Aires. Este último lito discoidal junto a numerosas PCPs integran un contexto arqueológico que ha sido fechado entre ca 10.725 y 10.270 años AP (Flegenheimer 2003). 
Los tres artefactos han sido confeccionados sobre arenisca silicificada. En el caso de la PCP la materia prima es de color gris y proviene de la Formación Salto Chico, cuyos afloramientos más cercanos se hallan a más de $70 \mathrm{~km}$, en la cuenca del río Uruguay. Los dos artefactos restantes han sido confeccionados en arenisca de color rojizo con cementación silícea. La misma no se encuentra disponible localmente donde fueron halladas las piezas. Este tipo de materia prima ha sido identificada en afloramientos primarios y secundarios de la cuenca basáltica del norte de Uruguay, en la cuenca del arroyo Catalán Chico y el río Cuareim medio (Suárez 2010), y en Argentina en el noreste de la provincia de Entre Ríos y en afloramientos de la Formación Butucatú en Corrientes (Castiñeira y Di Lello 2012, comunicación personal).

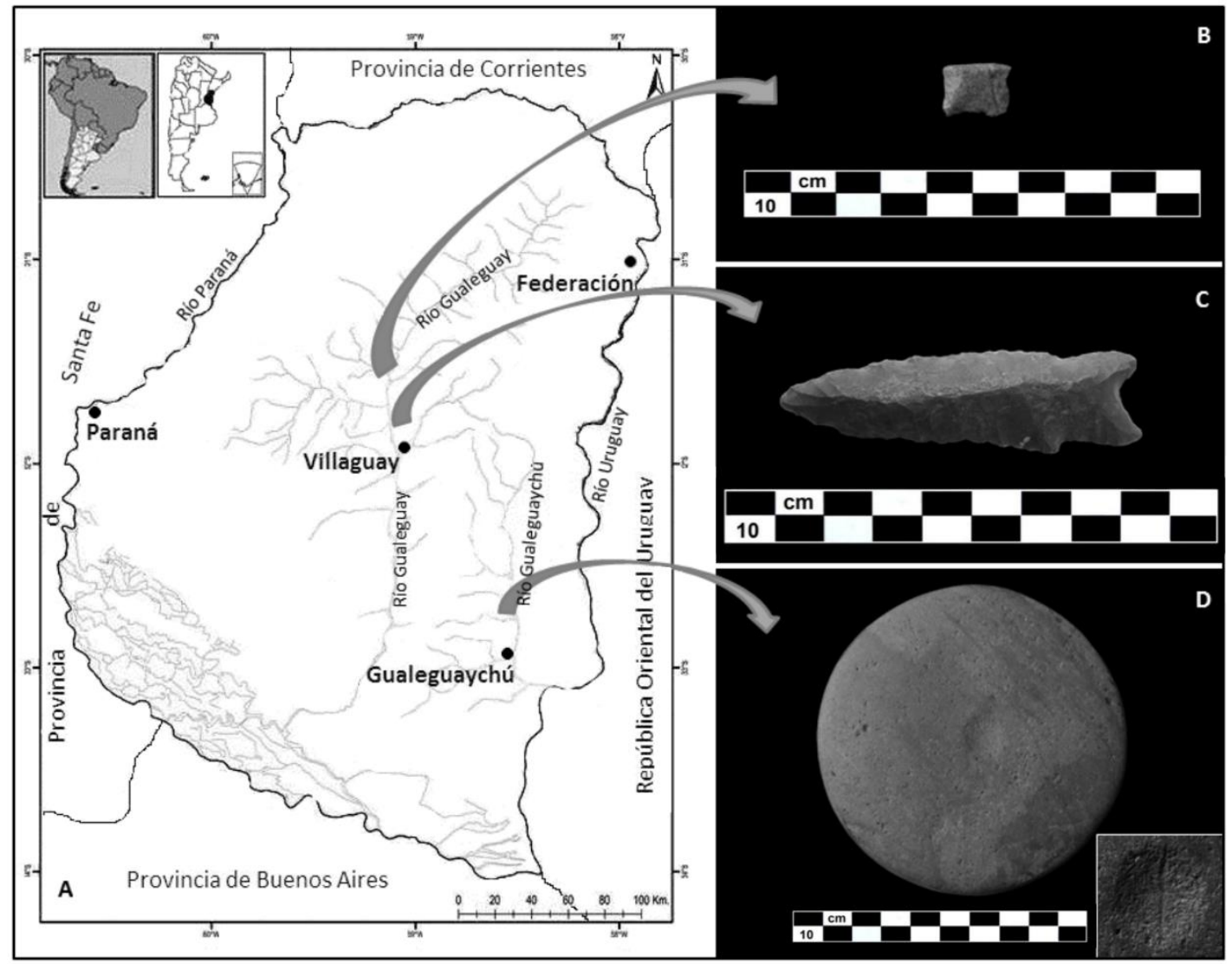

Figura 1. A) Mapa de la provincia de Entre Ríos mostrando la procedencia de los artefactos líticos. B) Pedúnculo de PCP. C) Punta Pay Paso. D) Lito discoidal y detalle del hoyuelo grabado.

\section{Consideraciones finales}

La evidencia presentada resulta novedosa ya que permite ampliar la dispersión geográfica de artefactos que, por sus características tecno-morfológicas, pueden ser considerados como indicadores de ocupaciones de la transición Pleistoceno/Holoceno. 
Las puntas cola de pescado han sido identificadas y datadas en Uruguay (Suárez 2011), sur de Brasil (Miller 1987) y en las regiones pampeana y patagónica de Argentina (Flegenheimer 2003; Miotti y Terranova 2015; Politis 1991). Asimismo, se han registrado cuatro PCP en Monte Caseros en la provincia de Corrientes (Mujica 1995; Nami 2007; Serrano 1932). En Entre Ríos solo había sido identificada hasta el momento una PCP, hallada en una colección y procedente del departamento Federación, pero no ha sido datada (Capeletti 2011). Por su parte, artefactos con características similares a las puntas Pay Paso solamente habían sido identificados hasta el momento en contextos arqueológicos del territorio uruguayo y brasileño (Suárez 2011, 2015a, 2015b). Por último, el estudio sistemático de los litos discoidales es relativamente reciente, y se habían identificado tales artefactos en Uruguay (López Romanelli 2012; Meneghin 2011; Nami 2013) y también en las regiones pampeana (Flegenheimer 2003) y patagónica (Jackson y Méndez 2007; Hermo et al. 2013).

Si bien es clara la función primaria de las puntas de proyectil como armas, no está determinada la función de la piedra discoidal, que junto a las demás registradas en el cono sur aún no han brindado evidencia concluyente sobre su uso. Sin embargo, dado el carácter de arte mobiliar paleoindio de la piedra discoidal con un diseño grabado, es probable que este objeto singular haya jugado un papel importante en el mundo simbólico de los pobladores tempranos de la región.

Si bien estos materiales considerados parte del equipamiento tecnológico paleoindio fueron recolectados en superficie, su presencia nos alerta sobre la potencialidad de esta región para el hallazgo de contextos arqueológicos tempranos. Asimismo, constituyen un estímulo para el abordaje sistemático de la problemática del poblamiento americano en el Nordeste argentino.

Agradecimientos: Al Museo Arqueológico Manuel Almeida, a Raúl Almeida, Miguel Lemes, Paulina Lemes y Facundo Astorga. A Rafael Suárez, Carola Castiñeira, Claudia Di Lello, Mariano Del Papa, Macelo Lugrin, Juan Carlos Bertolini y familia Beltrame. A Laura Miotti, Darío Hermo, Mariano Bonomo y Gustavo Politis por la lectura crítica y correcciones del manuscrito. Agradecemos especialmente a Marianela Fernández Lapalma por su ayuda en la edición de las fotografías.

\section{Bibliografía citada}

Capeletti L.

2011 Primer hallazgo de una punta de proyectil "cola de pescado" en la provincia de Entre Ríos. Revista del Museo de La Plata. Arqueología 12: 86. 
Castiñeira, C.; Charlin, J.; Cardillo, M. y J. Baeza

2012 Exploring morphometric variations in Fishtail Projectile Points from Uruguay, Pampa and Patagonia. En Southbound: Late Pleistocene Peopling of Latin America, L. Miotti, M. Salemme, N. Flegenheimer y T. Goebel (eds.), pp. 57-61. Center for the Study of the First Americans. Special Edition Current Research in the Pleistocene, Texas.

Castro, J.

2013 Arqueología en el centro de la provincia de Entre Ríos (Argentina). Revista Arqueología 19(2): 287-304.

Flegenheimer, N.

2003 Cerro El Sombrero: a locality with a view. En Where the South Winds Blow. Ancient Evidence of Paleo South Americans, L. Miotti, M. Salemme y N. Flegenheimer (eds.), pp. 57-61. A\&M University Press, Texas.

Flegenheimer, N. y M. Zárate

1989 Paleoindian occupation at Cerro El Sombrero locality, Buenos Aires Province, Argentina. Current Research in the Pleistocene 4: 12-13.

Flegenheimer, M.; Mazzia, N. y M. Babot

2013 Estudios de detalle sobre una piedra discoidal pampeana. Intersecciones en Antropología 14: 499-505.

Hermo, D.; Terranova, E.; Marchionni, L.; Magnin, L.; Mosquera, B. y L. Miotti 2013 Piedras o litos discoidales en Norpatagonia: evidencias en la meseta de Somuncurá (Río Negro, Argentina). Intersecciones en Antropología 14: 507-512.

Jackson, D. y C. Méndez.

2007 Litos discoidales tempranos en contextos paleoindios de Sudamérica. Magallania 5(1): 75-84.

López Romanelli, F.

2012 El yacimiento Los Ciervos: hallazgos paleontológicos y geológicos en sedimentos de la transición Pleistoceno-Holoceno (Depto. De Lavalleja, Uruguay). Orígenes 11. Fundación Arqueología Uruguaya, Montevideo.

Meneghin, U.

2011 Observaciones sobre algunos artefactos líticos discoidales registrados en el Uruguay. Orígenes 10. Fundación Arqueología Uruguaya, Montevideo. 
Miller, E.

1987 Pesquisas arqueológicas paleoindígenas no Brasil Occidental. Estudios Atacameños 8: 37-61.

Miotti, L.

1995 Piedra Museo locality: a special place in the New World. Current Research in the Pleistocene 12: 36-38.

Miotti, L. y E. Terranova

2015 A hill full of points in Terra Incognita from Patagonia: notes and reflections for discussing the way and tempo of initial peopling. PaleoAmerica 1(2): 181-196.

Mujica, J.

1995 Puntas cola de pescado de la costa occidental del río Uruguay medio, litoral argentino. Comechingonia 8: 199-207.

Nami, H.

2007 Research in the Middle Negro River Basin (Uruguay) and the Paleoindian occupation of the Southern Cone. Current Anthropology 48(1): 164-174.

2011 Tecnología paleoindia de Sudamérica: nuevos experimentos y observaciones para investigar la secuencia de reducción Fell. Orígenes 9. Fundación Arqueología Uruguaya, Montevideo.

2013 Archaeology, paleoindian research and lithic technology in the Middle Negro River, Central Uruguay. Archaeological Discovery 1(1): 1-22.

Poenitz, E.

1970 Un yacimiento en el centro de Entre Ríos. Su relación con el problema del patrimonio arqueológico charrúa. Boletín de Arqueología 1: 21-38.

Politis, G.

1991 Fishtail projectile points in the Southern Cone of South America: an overview. En Clovis. Origins and Adaptations, R. Bonnichsen y K. Turnmire (eds.), pp. 287-303. Center of the Study of the First Americans. Oregon State University, Corvallis.

Prates, L.; Politis, G. y J. Steele

2013 Radiocarbon chronology of the early human occupation of Argentina. Quaternary International 301: 104-122.

Rodríguez, J.

2005 El poblamiento inicial de la cuenca del río Uruguay medio. XV Congreso Nacional de Arqueología Argentina. Universidad Nacional de Río Cuarto, Rio Cuarto. 
Rodríguez, J.

2006 El poblamiento y el proceso de la secuencia cultural prehistórica de la Cuenca del Plata. Folia Histórica del Nordeste 16: 139-159.

Serrano, A.

1932 Exploraciones arqueológicas en el río Uruguay Medio. Memorias del Museo de Paraná 2.

1972 Líneas fundamentales de la arqueología del Litoral (una tentativa de periodización). Publicaciones del Instituto de Antropología XXXII.

Suárez, R.

2010 Arqueología Prehistórica en la Localidad Arroyo Catalán Chico: Investigaciones Pasadas, Replanteo y Avances Recientes. Departamento de publicaciones CSIC, Universidad de la República, Montevideo.

2011 Arqueología durante la Transición Pleistoceno Holoceno: Componentes Paleoindios, Organización de la Tecnología y Movilidad de los Primeros Americanos en Uruguay. BAR International Series xxxx, Oxford.

2015a The paleoamerican occupation on plains of Uruguay: technology, adaptations, and mobility. PaleoAmerica 1(1): 88-104.

2015b Tecnología lítica y conjunto de artefactos utilizados durante el poblamiento temprano de Uruguay. Chungara 47(1): 43-54. 